\title{
Meta-analysis of the efficacy of treatments for newly diagnosed and relapsed/refractory multiple myeloma with del(17p)
}

\author{
Jinghua Liu', ${ }^{1,}$, Hui Yang ${ }^{1, *}$, Xiaochan Liang ${ }^{2}$, Yuxin Wang ${ }^{1}$, Jian Hou ${ }^{3}$, Yanqin Liu ${ }^{1}$, \\ Jigang Wang ${ }^{1}$ and Fan Zhou ${ }^{1}$ \\ ${ }^{1}$ Department of Hematology, The General Hospital of Shenyang Military, Shenyang, China \\ ${ }^{2}$ Department of Clinical Medicine, Shenyang Pharmaceutical University, Shenyang, China \\ ${ }^{3}$ Department of Hematology, The Myeloma and Lymphoma Center, Chang Zheng Hospital, The Second Military Medical \\ University, Shanghai, China \\ *These authors have contributed equally to this work \\ Correspondence to: Fan Zhou, email: 1079249735@qq.com \\ Keywords: multiple myeloma del(17p), carfilzomib, pomalidomide, lenalidomide, bortezomib \\ Received: February 17, $2017 \quad$ Accepted: May 06, $2017 \quad$ Published: June 27, 2017 \\ Copyright: Liu et al. This is an open-access article distributed under the terms of the Creative Commons Attribution License 3.0 \\ (CC BY 3.0), which permits unrestricted use, distribution, and reproduction in any medium, provided the original author and source \\ are credited.
}

\section{ABSTRACT}

We analyzed the treatment of newly diagnosed and relapsed/refractory multiple myeloma (NDMM/RRMM) patients with del(17p). Thirteen prospective studies that evaluated 3,187 MM patients, including 685with del(17p), were included in our metaanalysis. The incidence of del(17p) in NDMM and RRMM patients was similar (13\% vs. $14 \%$, respectively, $P=0.64, I^{2}=94 \%$ ). The overall response rate (ORR) to new agents was $40.5 \%$ and $67.1 \%$, respectively, in RRMM patients with or without $\operatorname{del}(17 p)\left(P=0.1, I^{2}=63.9 \%\right)$. NDMM patients with del(17p) treated with PAD (bortezomib, adriamycin, and dexamethasone) induction therapy followed by bortezomib maintenance therapy had higher progression-free survival (PFS) (25.7 vs. 12-14.6 months) and overall survival (OS) (62\% vs. $8 \%$ at 36 months) than those treated with PD (bortezomib and dexamethasone) or VAD (vincristine, adriamycin, and dexamethasone). PFS among RRMM patients with del(17p) treated with D (singleagent dexamethasone), Rd/VRd (lenalidomide and dexamethasone/bortezomib and Rd), KRd (carfilzomib and Rd), IRd (ixazomib and Rd), ERd (elotuzumab and Rd), or P+D (pomalidomide and dexamethasone) was 1.1, 2-14.9, 24.5, 15.7, 21.2, and 4.6-7.3 months, respectively. The OS of patients treated with $D$ or $K$ (single-agent carfilzomib), Rd/VRd, ERd, or P+D was 7.7, 7, 4.7-36.4, > 42.3, and 12-12.6 months, respectively. PFS among RRMM patients without del(17p) treated with $D, R d / V R d$, ERd, or P+D was 2.3, 8.2-14.8, 18.5, and 4.2 months, while OS was 9, 23-40.8, 42.3, and 14 months, respectively. Thus bortezomib maintenance therapy improves the prognosis of NDMM patients with del(17p). Combined treatment with carfilzomib or elotuzumab and Rd, or pomalidomide with low-dose dexamethasone, improves the outcomes of RRMM patients with $\operatorname{del}(17 p)$.

\section{INTRODUCTION}

Multiple myeloma is a heterogeneous B-cell malignancy. The median overall survival (OS) is $2-10$ or more years and is dependent upon host factors, tumor burden, cytogenetic abnormalities (CAs), and therapeutic response [1-3]. High-risk CAs include del(17p), t(4;14), $t(14 ; 16)$, and $t(14: 20)[2,4]$. The frequency of $t(14 ; 20)$ is $1 \%$. The adverse impact of $\mathrm{t}(14: 16)$ can be abrogated by double autologous hematopoietic stem cell transplantation 
(auto-HSCT) [5]. Bortezomib improves the prognosis of patients with $\mathrm{t}(4 ; 14)$. Tandem auto-HSCT prolonged survival in patients with $\mathrm{t}(4 ; 14)$ [6-7]. TP53 (chromosome $17 \mathrm{p}$ ) is deleted in 7\% of myelomas. TP53 deletion induces clonal immortalization and promotes tumor cell survival. The presence of del(17p) is associated with reduced OS in myeloma patients, despite treatment with proteasome inhibitors and immunomodulatory drugs [8].

Bortezomib is a first generation proteasome inhibitor. Several randomized trials have evaluated bortezomib for induction, consolidation, or maintenance therapy in MM patients with del(17p). Bortezomib/dexamethasone did not improve the outcomes of patients with del(17p) in IFM2005-01 [9]. In contrast, bortezomib-based induction and maintenance therapy improved the outcomes of del(17p) patients in HOVON65/GMMG-HD4. However, OS was lower in these patients compared to those without del(17p) [10]. Lenalidomide and pomalidomide are immunomodulatory drugs. There is limited data on the effectiveness of lenalidomide as a first-line therapy for MM patients with del(17p). Treatment of relapsed/refractory multiple myeloma (RRMM) patients with del(17p) with lenalidomide alone or in combination with dexamethasone (Rd) has shown inconsistent results [11-13, 18]. The combination of carfilzomib or elotuzumab and $\mathrm{Rd}$ improved the outcomes of $\operatorname{del}(17 \mathrm{p})$ patients $[13,22]$. The same results were observed in RRMM patients with del(17p) treated with pomalidomide/dexamethasone [14]. We performed a meta-analysis of 13 studies to investigate the treatment of RRMM patients with del(17p) in order to determine the optimal therapeutic regimen.

\section{RESULTS}

\section{Study characteristics}

Overall, 162 studies were retrieved using the search strategy. Thirteen were included in the meta-analysis [914, 16-22]. The exclusion criteria are shown in Figure 1. The study characteristics are shown in Tables 1-2. One study reported the outcomes of NDMM patients with $\operatorname{del}(17 \mathrm{p})$ treated with VAD (vincristine, adriamycin, and dexamethasone), three reported the outcomes of bortezomib combination regimens in NDMM patients with del(17p), three reported the outcomes of lenalidomide combination regimens in RRMM patients with del(17p), three reported the outcomes of pomalidomide combination regimens in RRMM patients with $\operatorname{del}(17 \mathrm{p})$, and three reported the outcomes of carfilzomib combination regimens in RRMM patients with del(17p) (Figure 2).

$$
\begin{aligned}
& \text { Retrieved articles }(\mathbf{n = 1 6 2}) \\
& \text {-Cochrane library database }(\mathbf{n = 4 1 )} \\
& \text {-EMBASE database }(\mathbf{n = 1 0 6}) \\
& \text {-PubMed database }(\mathbf{n = 1 5})
\end{aligned}
$$$$
\text { Excluded: }
$$$$
\text { -Duplicates }(\mathbf{n}=\mathbf{5 6})
$$$$
\text { Excluded: }
$$$$
\text { - HR CA (del(17p) +t }(4 ; 14)(n=67)
$$$$
\text { -Studies didn't provide sufficient information to allow the calculation }
$$$$
\text { of ORR or PFS or OS }(\mathbf{n = 2 1 )}
$$

\section{Eligible articles $(n=13)$}

Figure 1: Flowchart of study inclusion. 
Table 1: NDMM study characteristics

\begin{tabular}{|c|c|c|c|c|c|c|c|c|}
\hline \multirow[t]{2}{*}{ Author, year } & \multirow{2}{*}{$\begin{array}{l}\text { Age } \\
\text { (M) }\end{array}$} & \multirow[t]{2}{*}{ Regimen } & \multicolumn{3}{|c|}{ Del(17) } & \multicolumn{3}{|c|}{ No Del(17) } \\
\hline & & & $\mathbf{n}$ & PFS(m) & OS (m) & $\mathbf{n}$ & PFS(m) & OS (m) \\
\hline $\begin{array}{l}\text { Avet-Loisea } \\
2007 \text { [17] }\end{array}$ & 49 & 4VAD + auto-HSCT & 58 & 14.6 & 22.4 & 474 & 34.7 & $75 \%$ at $41 \mathrm{~m}$ \\
\hline \multirow[t]{2}{*}{$\begin{array}{l}\text { Avet-Loisea } \\
2010 \text { [9] }\end{array}$} & 57 & $4 \mathrm{PD}+$ auto-HSCT & 54 & 14 & $50 \%$ at $48 \mathrm{~m}$ & 453 & 36 & $79 \%$ at $48 \mathrm{~m}$ \\
\hline & & $4 \mathrm{VAD}+$ auto-HSCT & 119 & 14 or so & $50 \%$ or so at $48 \mathrm{~m}$ & 393 & - & - \\
\hline \multirow[t]{2}{*}{$\begin{array}{l}\text { Neben } 2012 \\
{[10]}\end{array}$} & 57 & $\begin{array}{l}3 \mathrm{PAD}+\text { auto-HSCT }+ \\
\text { bortezomib maintenance } \\
1 / 2 \mathrm{w} \text { for } 2 \text { years }\end{array}$ & 37 & 25.7 & $62 \%$ at $36 \mathrm{~m}$ & 313 & 36 & $85 \%$ at $36 \mathrm{~m}$ \\
\hline & & $\begin{array}{l}3 \mathrm{VAD}+\text { auto-HSCT }+ \\
\text { thalidomide maintenance } \\
50 \mathrm{mg} \text { for } 2 \text { years }\end{array}$ & & 12 & $8 \%$ at $36 \mathrm{~m}$ & & & $80 \%$ at $36 \mathrm{~m}$ \\
\hline \multirow[t]{2}{*}{$\begin{array}{l}\text { Mateo } 2011 \\
{[16]}\end{array}$} & 73 & $\begin{array}{l}\text { VMP one 6-week } \\
+ \text { five } 5 \text {-week }+ \text { VP } \\
\text { maintenance up to } 3 \\
\text { years }\end{array}$ & 24 & 24 & 27 & 208 & 33 & $75 \%$ at $36 \mathrm{~m}$ \\
\hline & & $\begin{array}{l}\text { VTP one 6-week }+ \\
\text { five } 5 \text {-week }+ \text { VT } \\
\text { maintenance up to } 3 \\
\text { years }\end{array}$ & & & & & & \\
\hline
\end{tabular}

VAD, vincristine, adriamycin, and dexamethasone; PD, bortezomib and dexamethasone; PAD, bortezomib, adriamycin, and dexamethasone; VMP, bortezomib, melphalan, and prednisone; VP, bortezomib and prednisone; VTP, bortezomib, thalidomide, and prednisone; VT, bortezomib and thalidomide; auto-HSCT autologous hematopoietic stem cell transplantation.

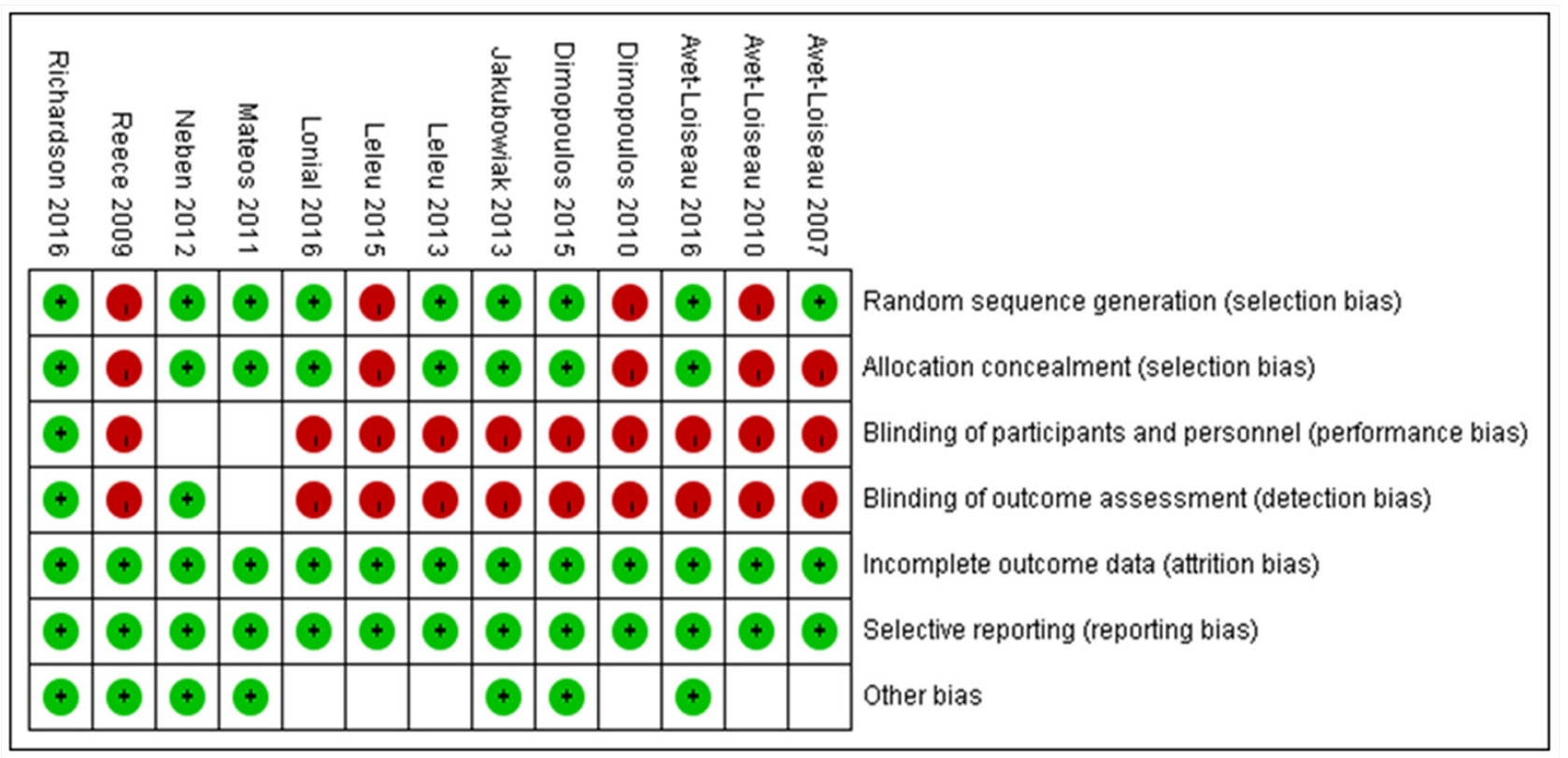

Figure 2: Quality of the studies. Green circle represents low risk, red circle represents high risk and white square represents unclear risk. 
Table 2: RRMM study characteristics

\begin{tabular}{|c|c|c|c|c|c|c|c|c|c|c|c|}
\hline $\begin{array}{l}\text { Author, year } \\
\text { regimen }\end{array}$ & Group & $\mathbf{n}$ & TFD (Y) (M) & NPT & $\begin{array}{c}\text { Bor } \\
\%\end{array}$ & $\begin{array}{c}\text { Lena } \\
\%\end{array}$ & $\begin{array}{c}\text { Thal } \\
\%\end{array}$ & $\begin{array}{c}\text { Tran } \\
\%\end{array}$ & ORR & $\begin{array}{l}\text { PFS } \\
(\mathrm{m})\end{array}$ & $\begin{array}{l}\text { OS } \\
(\mathbf{m})\end{array}$ \\
\hline \multirow[t]{2}{*}{$\begin{array}{l}\text { Reece } 2009 \\
R+/-D[11]\end{array}$} & $\operatorname{del}(17 \mathrm{p} 13)$ & 12 & 1.84 & $\begin{array}{l}\geq 3 \\
75 \%\end{array}$ & 50 & 0 & 66.7 & 75 & $58.3 \%$ & 2.2 & 4.7 \\
\hline & no $\operatorname{del}(17 \mathrm{p} 13)$ & 118 & 3.63 & $\begin{array}{l}\geq 3 \\
47 \%\end{array}$ & 44.9 & 0 & 52.5 & 72 & $85.6 \%$ & 8.2 & 23.7 \\
\hline \multirow[t]{2}{*}{$\begin{array}{l}\text { Jakubowiak } \\
2013 \text { K [19] }\end{array}$} & $\operatorname{del}(17 \mathrm{p} 13)$ & 30 & 5.3 & $\begin{array}{c}5(2- \\
12)\end{array}$ & 100 & \multicolumn{2}{|c|}{100} & 72.6 & $16.7 \%$ & - & 7 \\
\hline & no $\operatorname{del}(17 \mathrm{p} 13)$ & 199 & & & & & & & $26.1 \%$ & - & - \\
\hline \multirow[t]{2}{*}{$\begin{array}{l}\text { Avet-Loiseau } \\
2016 \text { KRd [12] }\end{array}$} & $\operatorname{del}(17 \mathrm{p} 13)$ & 13 & - & $\begin{array}{c}2.0 \\
(1-4)\end{array}$ & 81.3 & 27.1 & - & 79.2 & $76.9 \%$ & 24.5 & - \\
\hline & no $\operatorname{del}(17 \mathrm{p} 13)$ & 182 & & & & & & & $89 \%$ & - & - \\
\hline \multirow[t]{2}{*}{$\mathrm{Rd}$} & $\operatorname{del}(17 \mathrm{p} 13)$ & 13 & - & $\begin{array}{c}2.0 \\
(1-3)\end{array}$ & 67.3 & 23.1 & - & 59.6 & $46.2 \%$ & 11.1 & - \\
\hline & no $\operatorname{del}(17 \mathrm{p} 13)$ & 209 & & & & & & & $71.8 \%$ & - & - \\
\hline \multirow[t]{2}{*}{$\begin{array}{l}\text { Dimopoulos } \\
2010 \text { Rd [18] }\end{array}$} & $\operatorname{del}(17 \mathrm{p} 13)$ & 3 & 2.8 & $\begin{array}{l}\geq 3 \\
48 \%\end{array}$ & 76 & 0 & 76 & 0 & 0 & 2 & 9 \\
\hline & no $\operatorname{del}(17 \mathrm{p} 13)$ & 47 & & & & & & & $63 \%$ & 9.9 & 23 \\
\hline \multirow[t]{2}{*}{ VRd } & $\operatorname{del}(17 \mathrm{p} 13)$ & 7 & 3 & $\begin{array}{l}\geq 3 \\
46 \%\end{array}$ & 80 & 0 & 88 & 0 & $29 \%$ & 3 & 9 \\
\hline & no $\operatorname{del}(17 \mathrm{p} 13)$ & 42 & & & & & & & $73 \%$ & 9.9 & 23 \\
\hline \multirow[t]{2}{*}{$\begin{array}{l}\text { Leleu } 2013 \\
\mathrm{P}+\mathrm{D}[21]\end{array}$} & $\operatorname{del}(17 \mathrm{p} 13)$ & 15 & 5.9 & $\begin{array}{l}\geq 6 \\
23 \%\end{array}$ & 100 & 100 & 73 & 81 & $33 \%$ & - & - \\
\hline & no $\operatorname{del}(17 \mathrm{p} 13)$ & 50 & & & & & & & $44 \%$ & - & - \\
\hline \multirow[t]{2}{*}{$\begin{array}{l}\text { Leleu } 2015 \\
\mathrm{P}+\mathrm{D}[20]\end{array}$} & $\operatorname{del}(17 \mathrm{p} 13)$ & 22 & 3 & $\begin{array}{l}\geq 3 \\
60 \%\end{array}$ & 96 & 100 & - & 78 & $32 \%$ & 7.3 & 12 \\
\hline & no $\operatorname{del}(17 \mathrm{p} 13)$ & 30 & & & & & & & - & - & - \\
\hline \multirow[t]{2}{*}{$\begin{array}{l}\text { Doimopoulos } \\
2015 \text { P+D [14] }\end{array}$} & $\operatorname{del}(17 \mathrm{p} 13)$ & 44 & 5.3 & $\begin{array}{c}5(2- \\
14)\end{array}$ & - & - & - & - & $31.8 \%$ & 4.6 & 12.6 \\
\hline & no $\operatorname{del}(17 \mathrm{p} 13)$ & 258 & & & & & & & - & 4.2 & 14 \\
\hline \multirow[t]{2}{*}{$\mathrm{D}$} & $\operatorname{del}(17 \mathrm{p} 13)$ & 23 & 6.1 & $\begin{array}{c}5(2- \\
17)\end{array}$ & - & - & - & - & $4.3 \%$ & 1.1 & 7.7 \\
\hline & no $\operatorname{del}(17 \mathrm{p} 13)$ & 130 & & & & & & & - & 2.3 & 9.0 \\
\hline \multirow[t]{2}{*}{$\begin{array}{l}\text { Richardson } \\
2016 \text { IRd [22] }\end{array}$} & $\operatorname{del}(17 \mathrm{p} 13)$ & 33 & - & - & - & - & - & - & - & 15.7 & - \\
\hline & no $\operatorname{del}(17 \mathrm{p} 13)$ & 519 & & & & & & & - & - & - \\
\hline \multirow[t]{2}{*}{$\begin{array}{l}\text { Lonial } 2016 \\
\text { ERd [13] }\end{array}$} & $\operatorname{del}(17 \mathrm{p} 13)$ & 102 & - & $\begin{array}{l}\geq 3 \\
16 \%\end{array}$ & 68 & 5 & 48 & 52 & - & 21.2 & NR \\
\hline & no del(17p13) & 213 & - & & & & & & - & 18.5 & 42.3 \\
\hline \multirow[t]{2}{*}{$\mathrm{Rd}$} & $\operatorname{del}(17 \mathrm{p} 13)$ & 104 & - & $\begin{array}{l}\geq 3 \\
16 \%\end{array}$ & 71 & 6 & 48 & 57 & - & 14.9 & 36.4 \\
\hline & no $\operatorname{del}(17 \mathrm{p} 13)$ & 218 & - & & & & & & - & 14.8 & 40.8 \\
\hline
\end{tabular}

TFD, time from diagnosis; NPT, number of prior therapies; Bor, bortezomib; Lena, lenalidomide; Thal, thalidomide; Tran, stem cell transplantation; ORR, overall response rate; NR, not reached. 


\section{Incidence of del(17p) in NDMM and RRMM patients}

The incidence of NDMM with del(17p) was 10.3$18.1 \%$ in four studies. The pooled incidence of del( $17 \mathrm{p})$ was 13\% (95\% CI: 9-17\%). There was significant study heterogeneity $\left(I^{2}=86 \%, P<0.0001\right)$ (Figure 3$)$. The total incidence of RRMM with del(17p) was $6-32 \%$ in eight studies. The Leleu et al. study was excluded because only del(17p) and $t(4 ; 14)$ MM patients were included. The pooled incidence of del( $17 \mathrm{p})$ was $14 \%(95 \%$ CI: $8-21 \%)$ with significant study heterogeneity $\left(I^{2}=96 \%, P<0.00001\right)$ (Figure 3). The incidence of del(17p) did not differ between NDMM and RRMM patients $\left(P=0.64, I^{2}=94 \%\right)$.

\section{Response rate to therapy in RRMM patients with and without del(17p)}

Seven trials that enrolled a total of 1,447 RRMM patients (including 182 patients with del(17p)) evaluated the effects of treatment on ORR. The regimen included D (single-agent dexamethasone), Rd/RD (lenalidomide and dexamethasone), VRd (bortezomib and Rd), K (singleagent carfilzomib), KRd (carfilzomib and Rd), and $\mathrm{P}+\mathrm{D}$ (pomalidomide and dexamethasone). The ORR to D was $4.3 \%$ in patients with del $(17 \mathrm{p})$ in one study. The ORR to
$\mathrm{K}$ was $16.7 \%$ in one study. The ORR to Rd was variable in three studies $(0 \%, 46.2 \%$, and $58.3 \%$, respectively). The ORR to $\mathrm{P}+\mathrm{D}$ was approximately $32 \%$ (indicating efficacy) in three studies, while the ORR to KRd was $76.9 \%$ in one study (Figure 4A). We compared the ORR to new agents in 86 patients with, and 805 patients without, del(17p). Pooled analysis showed that the ORR was $40.5 \%$ (95\% CI: $22.5-60.9 \%)$ in patients with and $67.1 \%$ in patients without del(17p) (95\% CI: 42.9-84.7\%) $\left(P=0.1, I^{2}=\right.$ 63.9\%) (Figure 4B).

\section{Survival of NDMM and RRMM patients with and without del(17p)}

PFS was evaluated in four trials: three that enrolled young patients following VAD or PD/PAD induction therapy and auto-HSCT, and one that enrolled older patients who were only treated with VMP/VTP. OS was evaluated in 1,740 NDMM patients (292 with del(17p) and 1,448 without del(17p)) (Figure 5A). PFS and OS were longer in del(17p) patients treated with PAD induction therapy followed by long-term bortezomib maintenance therapy compared to patients treated with PD or VAD induction therapy without bortezomib maintenance therapy ( 25.7 vs. $12-14.6$ months, and $62 \%$ vs. $8 \%$ at 36 months, respectively).

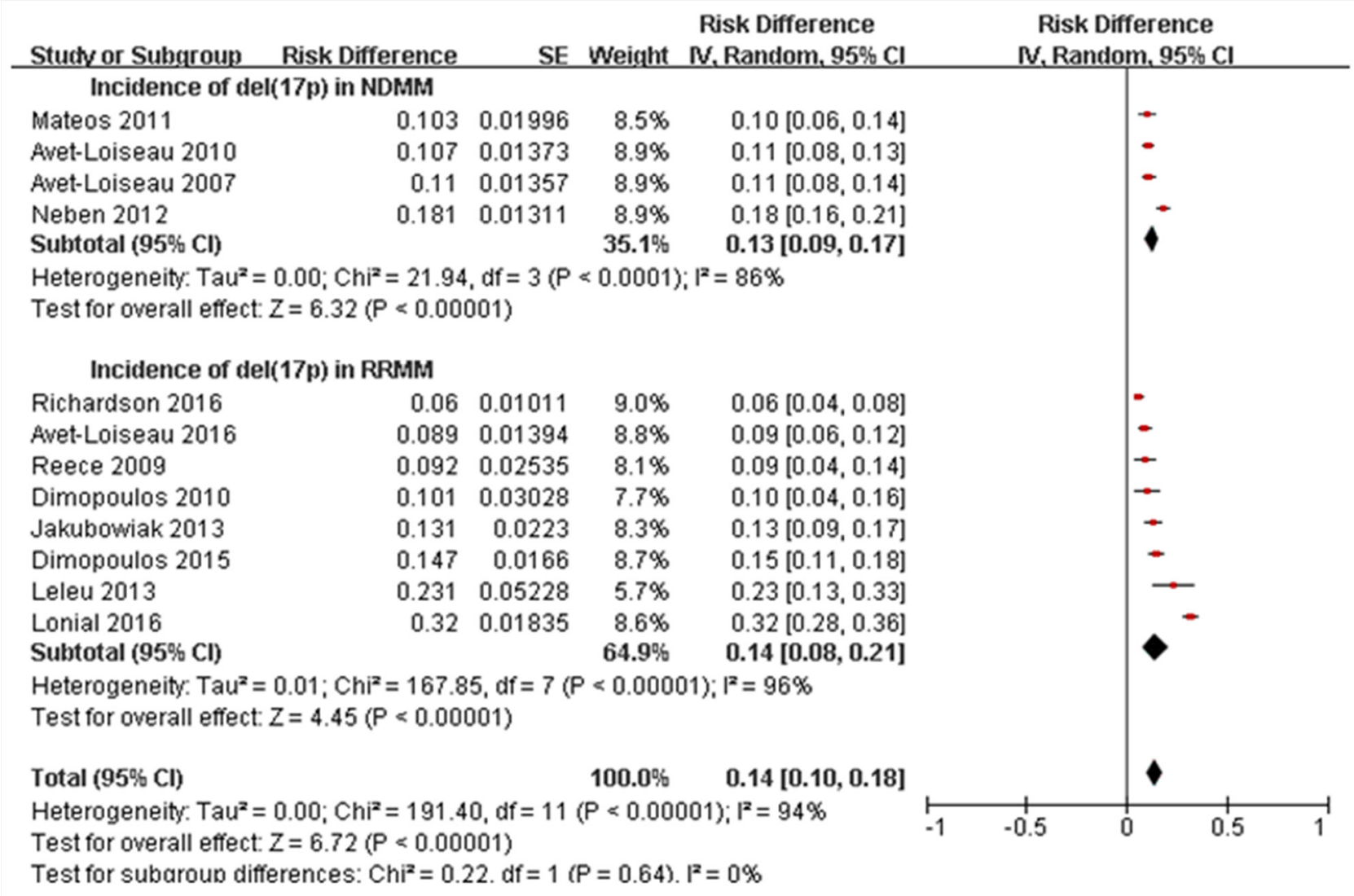

Figure 3: Meta-analysis of incidence of del(17p) in NDMM and RRMM. 
We evaluated PFS (Figure 5A) and OS (Figure 5B) in seven trials that included 1,419 RRMM patients (393 with and 1,026 without del(17p)). The PFS of del(17p) patients treated with $\mathrm{D}, \mathrm{Rd} / \mathrm{VRd}, \mathrm{KRd}$, IRd (ixazomib and $\mathrm{Rd}$ ), ERd (elotuzumab and Rd), or P+D was 1.1, 2-14.9, $24.5,15.7,21.2$, and 4.6-7.3 months, respectively. The OS of patients treated with $\mathrm{D}$ or $\mathrm{K}, \mathrm{Rd} / \mathrm{VRd}, \mathrm{ERd}$, or $\mathrm{P}+\mathrm{D}$ was 7.7, 7, 4.7-36.4, > 42.3, and 12-12.6 months, respectively. In $\operatorname{del}(17 p)$-negative patients, the PFS of $\mathrm{D}, \mathrm{Rd} / \mathrm{VRd}$, ERd, and $\mathrm{P}+\mathrm{D}$ was $2.3,8.2-14.8,18.5$, and 4.2 months, respectively. The OS of $\mathrm{D}, \mathrm{Rd} / \mathrm{VRd}, \mathrm{ERd}$, and $\mathrm{P}+\mathrm{D}$ was 9 , 23-40.8, 42.3, and 14 months, respectively.

\section{DISCUSSION}

The incidence of del(17p) in NDMM and RRMM patients was similar (13-14\%). Previous studies have demonstrated that del(17p) is a secondary genetic event in MM, while immunoglobulin heavy chain $(\operatorname{IgH})$ translocation is a primary event. Late events are generally

A

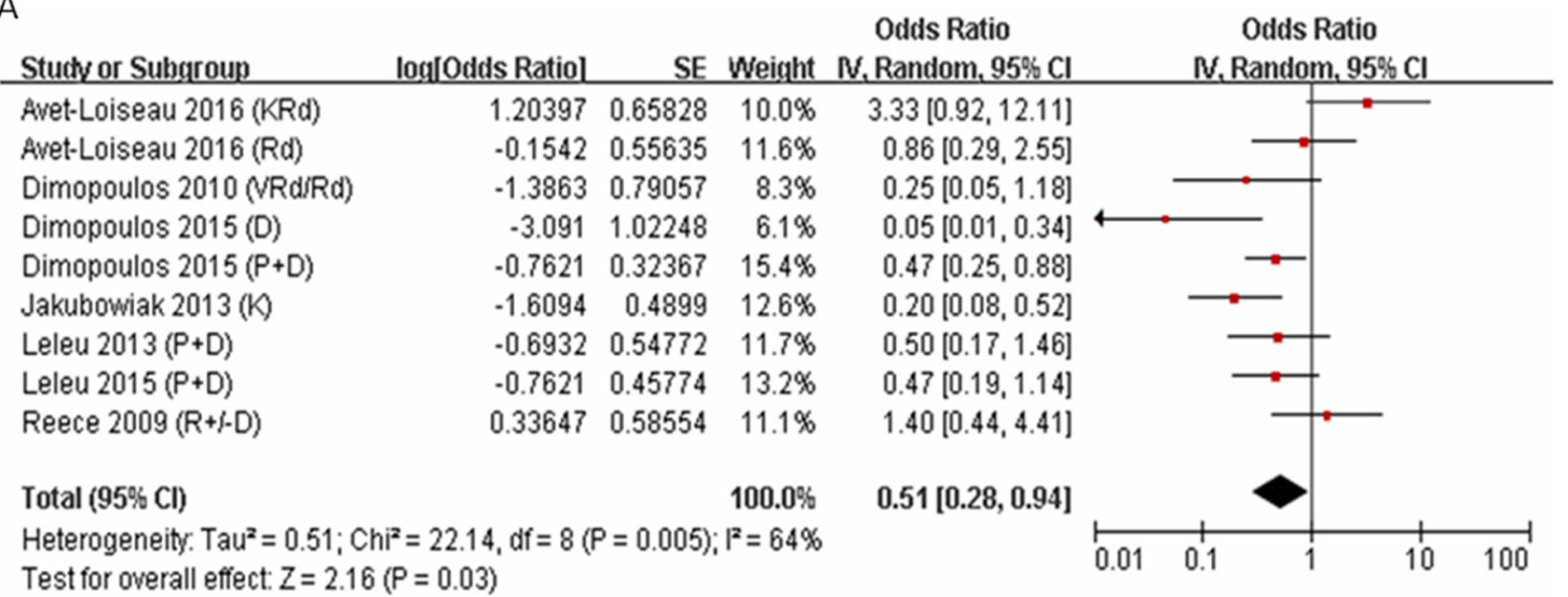

B

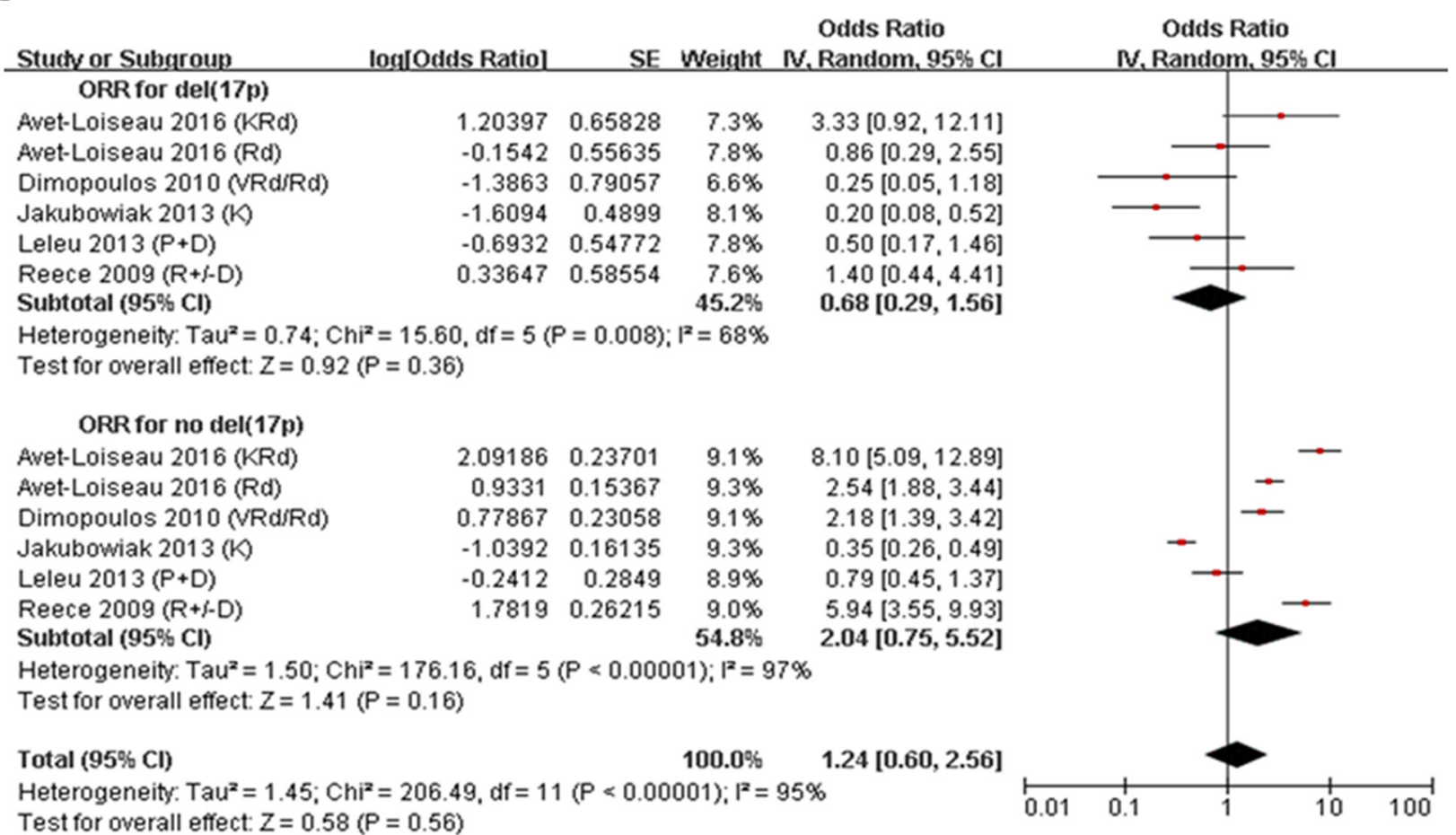

Test for subaroun differences: $\mathrm{Chi}^{2}=2.77 . \mathrm{df}=1(\mathrm{P}=0.10) . \mathrm{I}^{2}=63.9 \%$

Figure 4: Meta-analysis of overall response rate (ORR) in RRMM with del(17p) or no del(17p). (A) ORR to all regimen in RRMM with del(17p). (B) ORR to new agents in RRMM with del(17p) or no del(17p). ORR, over response rate; CI, confidence interval. 
indicative of more aggressive disease. Of patients with IgH translocations, $62 \%$ had $1 \mathrm{q}$ gain compared to $32.4 \%$ in controls [23]. The frequency of $\operatorname{del}(17 \mathrm{p})$ was similar to that of patients without $\mathrm{IgH}$ translocations. Among patients with IgH translocation and/or 1q gain, or del(17p), $20 \%$ shared $\geq 2$ CAs [1]. We investigated the treatment of NDMM and RRMM patients with del(17p). We selected studies with data for del(17p) only (not for high-risk CAs: $\operatorname{del}(17 p)$ and $t(4 ; 14))$. The cut-off value for the proportion of plasma cells with del( $17 \mathrm{p})$ was $\geq 60 \%$.

Pineda-Roman et al. [24] and Shaughnessy et al. [8] reported that the introduction of bortezomib in the Total Therapy 3 program improved the prognosis of patients with $\mathrm{t}(4 ; 14)$ or del $(17 \mathrm{p})$. However, two other studies reported conflicting results, which may be explained by differences in study size, therapeutic strategy, or the number of bortezomib treatments. In the IFM experience, only four cycles (16 injections) of bortezomib were administered. In the HOVON-65/GMMG-HD4 [10], GEM05MAS65 [16], and Total Therapy 3 trials, patients received more than 64 injections of bortezomib. It is possible that only long-term bortezomib maintenance therapy can improve the poor prognosis of $\operatorname{del}(17 \mathrm{p})$ patients. HOVON-65/GMMG-HD4, a prospective randomized controlled trial, demonstrated an improvement of PFS and OS in patients who received long-term treatment with bortezomib compared to controls (25.7 vs. 12 months, and $62 \%$ vs. $8 \%$ at 36 months, respectively). However, the trial sample size was small, and the prognosis of del(17p) patents was still worse than that of patients without $\operatorname{del}(17 \mathrm{p})$.

A

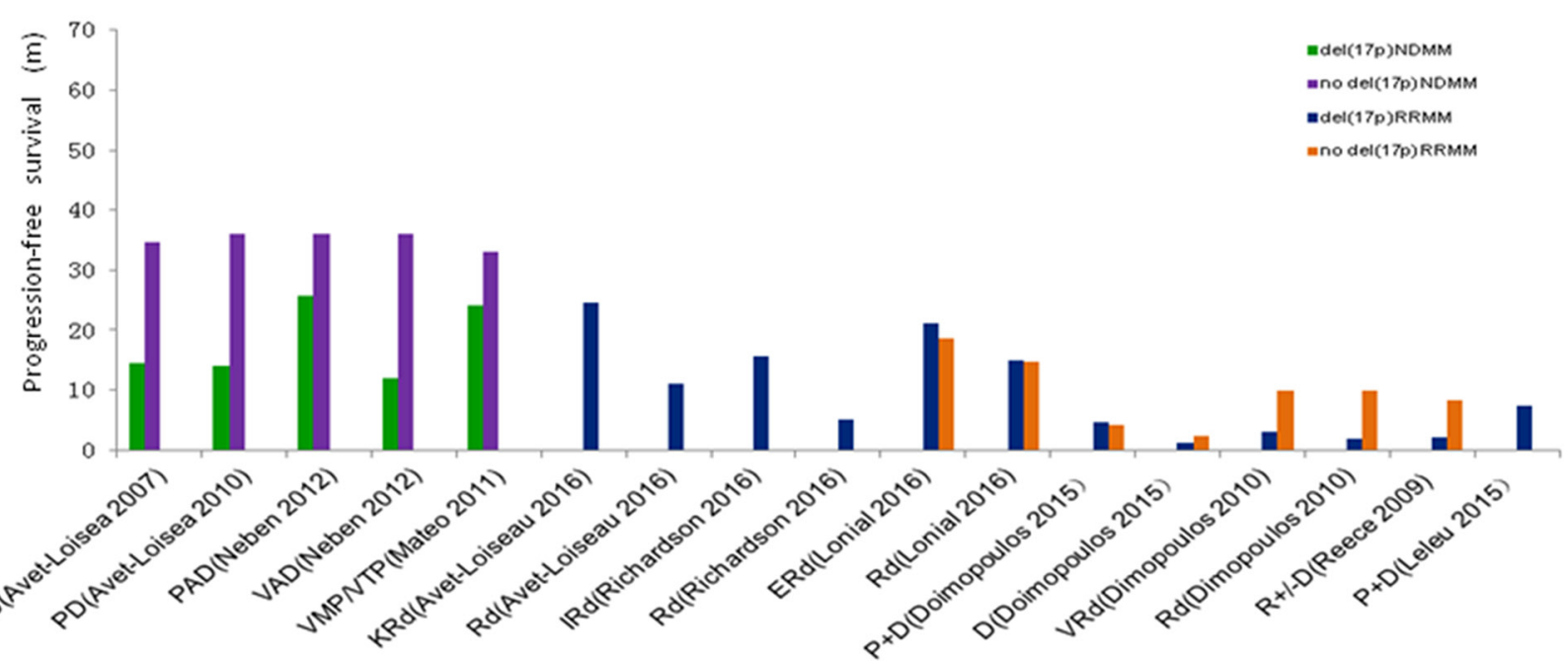

$\mathrm{B}$

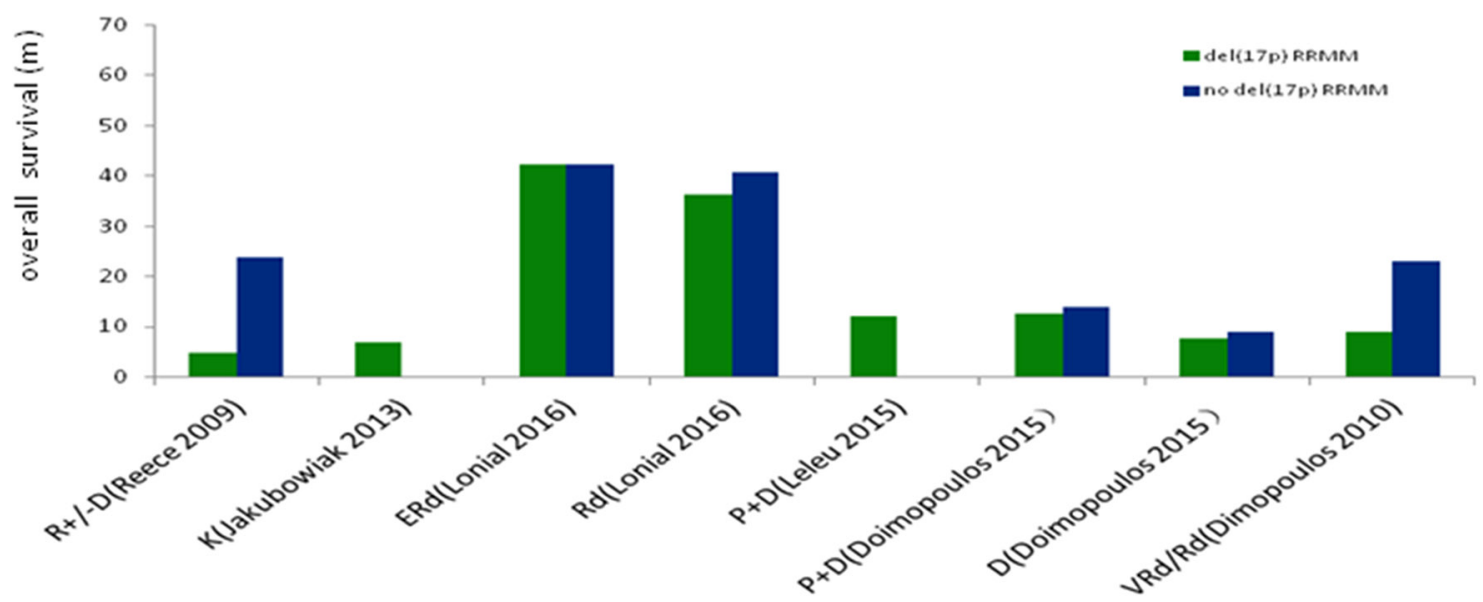

Figure 5: Progression-free survival (PFS) and over survival (OS) of NDMM or RRMM with del(17p) or no del(17p). (A) PFS of NDMM or RRMM with del(17p) or no del(17p). (B) OS of RRMM with del(17p) or no del(17p). VAD, vincristine adriamycin and dexamethasone; $\mathrm{P}+\mathrm{D}$, pomalidomide and dexamethasone; $\mathrm{PAD}$, bortezomib adriamycin and dexamethasone; VMP, bortezomib melphalan and prednisone; VP, bortezomib and prednisone; VTP, bortezomib thalidomide and prednisone; K, carfilzomib; Rd, lenalidomide and dexamethasone; I, ixazomib; E, elotuzumab. 
The presence of del(17p) in RRMM patients is associated with lower treatment response rates and reduced PFS and OS. The detrimental effect of del(17p) was demonstrated in patients treated with lenalidomide and dexamethasone combination therapy, with or without the addition of bortezomib [11, 18]. Lonial et al. [13] reported higher PFS and OS, which could be explained by the fact that $49 \%$ of their patients received one previous therapeutic regimen. There is a need for novel therapeutic approaches for this highly refractory patient subgroup. Pomalidomide has anti-myeloma and immunomodulatory effects. It also inhibits stromal cell adhesion. The MM-003 and IFM2010-02 trials of pomalidomide in combination with low-dose dexamethasone found that combination therapy improved the outcomes of RRMM patients with del(17p) [14, 20]. However, patients in the IFM2010-02 study had early relapse.

Carlzomib is an epoxyketone proteasome inhibitor that binds selectively and irreversibly to the immunoproteasome. Carlzomib as a single-agent had an encouraging ORR of $16.7 \%$ in $\operatorname{del}(17 \mathrm{p})$ patients [19]. The ORR was $76.9 \%$ in patients treated with carfilzomib, lenalidomide, and dexamethasone. An improvement in PFS (24.5 months) was also observed, which was a 9-month improvement compared to patients treated with lenalidomide and dexamethasone [12]. However, the study size was relatively small. In the TOURMALINE-MM1 study of ixazomib (a proteasome inhibitor), lenalidomide, and dexamethasone compared to Rd in patients with del(17p), the PFS HRs favored ixazomib, lenalidomide, and dexamethasone vs. Rd [22].

Elotuzumab is a first-in-class humanized immunoglobulin G1 immuno-stimulatory monoclonal antibody targeting SLAMF7/CS1. In the ELOQUENT-2 study, PFS and OS were longer in RRMM patients with del $(17 p)$ treated with elotuzumab, lenalidomide, and dexamethasone compared to those treated with $\mathrm{Rd}$, and were even longer than in patients without del(17p) [13]. Elotuzumab has a dual mechanism of action. It promotes antibody-dependent, cell-mediated cytotoxicity, and directly activates natural killer cells through SLAMF7 receptors in an Fc-independent process. Elotuzumab activates CD16deficient natural killer cells (CD16 is required for antibodydependent, cell-mediated cytotoxicity), which further supports the direct immunotherapeutic role of elotuzumab in activating natural killer cells [25].

Our results indicate bortezomib maintenance therapy improves PFS and OS in patients with del(17p). Combined treatment with carfilzomib or elotuzumab and $\mathrm{Rd}$, or pomalidomide with low-dose dexamethasone, can improve the outcomes of RRMM patients with del(17p).

\section{MATERIALS AND METHODS}

\section{Search strategy}

We searched the PubMed, Embase, and Cochrane Library databases, and conference proceedings from the American Society of Hematology, the European Hematology Association, and the American Society of Clinical Oncology. The search terms were as follows: "myeloma" and "del(17p)". The reference lists from candidate studies and relevant review articles were screened manually. The study was approved by the Institutional Review Board of the General Hospital of Shenyang Military, and was performed in accordance with the Declaration of Helsinki.

\section{Eligibility criteria}

Studies were eligible for inclusion in the metaanalysis if they met all of the following criteria: (1) publication data prior to January 2017; (2) prospective analysis; (3) independent data for $\operatorname{del}(17 \mathrm{p}$ ) (not for high-risk cytogenetic abnormalities (CAs): $\operatorname{del}(17 \mathrm{p})$ and $\mathrm{t}(4 ; 14))$; and (4) provided sufficient information to allow calculation of the overall response rate (ORR), progression-free survival (PFS), and OS.

\section{Study selection}

All abstracts were independently reviewed by two investigators. Full-text screening and independent reviews were performed of eligible studies. Articles meeting the criteria at the full-text review stage were included in the meta-analysis. If multiple publications and/or conference abstracts reported on a single trial population, only the most recent or relevant data were selected for analysis.

\section{Data collection}

The following data were extracted for each study: the first author, publication year, study design, study level, enrollment period, number of patients with and without del(17p), patient characteristics (median age, sex, diagnosis [NDMM or RRMM], median time from diagnosis, median number of prior therapies, and previous regimen of bortezomib, lenalidomide, thalidomide, or auto-HSCT for RRMM patients, treatment details, efficacy (ORR $\geq$ partial response, PFS, and OS), and length of follow-up.

\section{Risk of bias in individual studies}

The Cochrane Collaborations tool was used to assess the risk of bias in randomized trials [15]. This assessment was conducted by two independent investigators. Differences were resolved through discussion with a third reviewer.

\section{Data analysis}

We calculated the pooled incidence of $\operatorname{del}(17 \mathrm{p})$ in NDMM and RRMM patients, and the ORR in RRMM patients with and without $\operatorname{del}(17 \mathrm{p})$ using Review 
Manager (version 5.3; the Cochrane Collaboration, Oxford, England). A random-effect model was used for all analyses, which incorporated the variability of trial results and provided a more conservative estimate of effect size by producing greater confidence intervals (CIs). Study heterogeneity was assessed using Chi squared tests and the $\mathrm{I}^{2}$ statistic. A $P<0.10$ and an $I^{2}>50 \%$ was considered significant. Because survival and hazard ratios (HRs) were not calculated at the same time-points in the included studies, we could not calculate a pooled survival estimate. Instead, we generated bar graphs of PFS and OS in NDMM or RRMM patients with or without del(17p) using SPSS version 16.0 (Chicago, Illinois, USA).

\section{ACKNOWLEDGMENTS} analysis.

We thank Han Deng for performing the statistical

\section{CONFLICTS OF INTEREST}

The authors declare that there are no conflicts of interest.

\section{REFERENCES}

1. Sonneveld P, Avet-Loiseau H, Lonial S, Usmani S, Siegel D, Anderson KC, Chng WJ, Moreau P, Attal M, Kyle RA, Caers J, Hillengass J, San Miguel J, et al. Treatment of multiple myeloma with high-risk cytogenetics: a consensus of the International Myeloma Working Group. Blood. 2016;127:2955-2962.

2. Rajkumar SV. CME information: multiple myeloma: 2016 update on diagnosis, risk-stratification and management. Am J Hematol. 2016;91: 719-734.

3. Palumbo A, Avet-Loiseau H, Oliva S, Lokhorst HM, Goldschmidt H, Rosinol L, Richardson P, Caltagirone S, Lahuerta JJ, Facon T, Bringhen S, Gay F, Attal M, et al. Revised international staging system for multiple myeloma: a report from International Myeloma Working Group. J Clin Oncol. 2015;33:2863-2869.

4. Fonseca R, Bergsagel PL, Drach J, Shaughnessy J, Gutierrez N, Stewart AK, Morgan G, Van Ness B, Chesi M, Minvielle S, Neri A, Barlogie B, Kuehl WM, et al. International Myeloma Working Group molecular classification of multiple myeloma: spotlight review. Leukemia. 2009;23:2210-2221.

5. Avet-Loiseau H, Malard F, Campion L, Magrangeas F, Sebban C, Lioure B, Decaux O, Lamy T, Legros L, Fuzibet JG, Michallet M, Corront B, Lenain P, et al. Translocation $\mathrm{t}(14 ; 16)$ and multiple myeloma: is it really an independent prognostic factor? Blood. 2011;117: 2009-2011.

6. Sonneveld P, Goldschmidt H, Rosinol L, Bladé J, Lahuerta JJ, Cavo M, Tacchetti P, Zamagni E, Attal M, Lokhorst HM, Desai A, Cakana A, Liu K, et al. Bortezomib-based versus nonbortezomib-based induction treatment before autologous stem-cell transplantation in patients with previously untreated multiple myeloma: a meta-analysis of phase III randomized, controlled trials. J Clin Oncol. 2013;31:3279-3287.

7. Moreau P, Attal M, Garban F, Hulin C, Facon T, Marit G, Michallet M, Doyen C, Leyvraz S, Mohty M, Wetterwald M, Mathiot C, Caillot D, et al. Heterogeneity of $t(4 ; 14)$ in multiple myeloma. Long-term follow-up of 100 cases treated with tandem transplantation in IFM99 trials. Leukemia. 2007;21:2020-2024.

8. Shaughnessy JD, Zhou Y, Haessler J, Van Rhee F, Anaissie E, Nair B, Waheed S, Alsayed Y, Epstein J, Crowley J, Barlogie B. TP53 deletion is not an adverse feature in multiple myeloma treated with Total Therapy 3. Br J Haematol. 2009;147:347-351.

9. Avet-Loiseau H, Leleu X, Roussel M, Moreau P, GuerinCharbonnel C, Caillot D, Marit G, Benboubker L, Voillat L, Mathiot C, Kolb B, Macro M, Campion L, et al. Bortezomib plus dexamethasone induction improves outcome of patients with $\mathrm{t}(4 ; 14)$ myeloma but not outcome of patients with del(17p). J Clin Oncol. 2010;28:4630-4634.

10. Neben K, Lokhorst HM, Jauch A, Bertsch U, Hielscher T, Holt BV, Salwender H, Blau LW, Weisel K, Pfreundschuh M, Scheid C, Duhrsen U, Lindemann W, et al. Administration of bortezomib before and after autologous stem cell transplantation improves outcome in multiple myeloma patients with deletion17p. Blood. 2012;119:940-948.

11. Reece D, Song KW, Fu T, Roland B, Chang H, Horsman DE, Mansoor A, Chen C, Masih-Khan E, Trieu Y, Bruyere $\mathrm{H}$, Stewart DA, Bahlis NJ, et al. Influence of cytogenetics in patients with relapsed or refractory multiple myeloma treated with lenalidomide plus dexamethasone: adverse effect of deletion 17p13. Blood. 2009; 114: 522-525.

12. Avet-Loiseau H, Fonseca R, Siegel D, Dimopoulos MA, Špička I, Masszi T, Hájek R, Rosiñol L, GoranovaMarinova V, Mihaylov G, Maisnar V, Mateos MV, Wang M, et al. Carfilzomib significantly improves the progressionfree survival of high-risk patients in multiple myeloma. Blood. 2016; 128:1174-1180.

13. Lonial S, Dimopoulos M, Palumbo A, White D, Grosicki S, Spicka I, Walter-Croneck A, Moreau P, Mateos MV, Magen H, Belch A, Reece D, Beksac M, et al.; ELOQUENT-2 Investigators. Elotuzumab therapy for relapsed or refractory multiple myeloma. N Engl J Med. 2015;373:621-631.

14. Dimopoulos MA, Weisel KC, Song KW, Delforge M, Karlin L, Goldschmidt H, Moreau P, Banos A, Oriol A, Garderet L, Cavo M, Ivanova V, Alegre A, et al. Cytogenetics and longterm survival of patients with refractory or relapsed and refractory multiple myeloma treated with pomalidomide and low-dose dexamethasone. Haematol. 2015;100:1327-1333.

15. Higgins JP, Altman DG, Gotzsche PC, Jüni $P$, Moher D, Oxman AD, Savović J, Schulz KF, Weeks L, Sterne JA. The Cochrane Collaboration's tool for assessing risk of bias in randomised trials. BMJ. 2011;343:7829. 
16. Mateos MV, Gutierrez NC, Martin Ramos ML, Paiva B, Montalbán MA, Oriol A, Martínez-López J, Teruel AI, Bengoechea E, Martín A, Díaz-Mediavilla J, De Arriba F, Palomera L, et al. Outcome according to cytogenetic abnormalities and DNA ploidy in myeloma patients receiving short induction with weekly bortezomib followed by maintenance. Blood. 2011;118:4547-4553.

17. Avet-Loiseau H, Attal M, Moreau P, Charbonnel C, Garban F, Hulin C, Leyvraz S, Michallet M, Yakoub-Agha I, Garderet L, Marit G, Michaux L, Voillat L, et al. Genetic abnormalities and survival in multiple myeloma: the experience of the Intergroupe Francophone du Myelome. Blood. 2007;109:3489-3495.

18. Dimopoulos MA, Kastritis E, Christoulas D, Migkou M, Gavriatopoulou M, Gkotzamanidou M, Iakovaki M, Matsouka C, Mparmparoussi D, Roussou M, Efstathiou E, Terpos E. Treatment of patients with relapsed/refractory multiple myeloma with lenalidomide and dexamethasone with or without bortezomib: prospective evaluation of the impact of cytogenetic abnormalities and of previous therapies. Leukemia. 2010;24:1769-1778.

19. Jakubowiak AJ, Siegel DS, Martin T, Wang M, Vij R, Lonial S, Trudel S, Kukreti V, Bahlis N, Alsina M, ChananKhan A, Buadi F, Reu FJ, et al. Treatment outcomes in patients with relapsed and refractory multiple myeloma and high-risk cytogenetics receiving single-agent carlzomib in the PX-171-003-A1 study. Leukemia. 2013;27:2351-2356.

20. Leleu X, Karlin L, Macro M, Hulin C, Garderet L, Roussel M, Arnulf B, Pegourie B, Kolb B, Stoppa AM, Brechiniac S, Marit G, Thielemans B, et al. Pomalidomide plus lowdose dexamethasone in multiple myeloma with deletion $17 \mathrm{p}$ and/or translocation(4;14): IFM2010-02 trial results. Blood. 2015;125:1411-1417.
21. Leleu X, Attal M, Arnulf B, Moreau P, Traulle C, Marit G, Mathiot C, Petillon MO, Macro M, Roussel M, Pegourie B, Kolb B, Stoppa AM, et al. Pomalidomide plus lowdose dexamethasone is active and well tolerated in bortezomib and lenalidomide-refractory multiple myeloma: Intergroupe Francophone du Myelome 2009-02. Blood. 2013;121:1968-1975.

22. Richardson PG, Avet-Loiseau H, Palumbo A, Viterbo L, Nagler A, Ganly P, Yehuda DB, Miguel JS, Rajkumar SV, Pour L, Langer C, Bahlis NJ, Pluta A, et al. Efficacy and safety of ixazomib plus lenalidomide-dexamethasone (IRd) vs placebo-rd in patients (pts) with relapsed/refractory multiple myeloma (RRMM) by cytogenetic risk status in the global phase III Tourmaline-MM1 study. J Clin Oncol. 2016; 34:8018.

23. Boyd KD, Ross FM, Chiecchio L, Dagrada GP, Konn ZJ, Tapper WJ, Walker BA, Wardell CP, Gregory WM, Szubert AJ, Bell SE, Child JA, Jackson GH, et al. A novel prognostic model in myeloma based on cosegregating adverse FISH lesions and the ISS: analysis of patients treated in the MRC Myeloma IX trial. Leukemia. 2012;26:349-355.

24. Pineda-Roman M, Zangari M, Haessler J, Anaissie E, Tricot G, Van Rhee F, Crowley J, Shaughnessy JD Jr, Barlogie B. Sustained complete remissions in multiple myeloma linked to bortezomib in total therapy 3: comparison with total therapy 2. Br J Haematol. 2008;140:625-634.

25. Collins SM, Bakan CE, Swartzel GD, Hofmeister CC, Efebera YA, Kwon H, Starling GC, Ciarlariello D, Bhaskar S, Briercheck EL, Hughes T, Yu J, Rice A, et al. Elotuzumab directly enhances NK cell cytotoxicity against myeloma via CS1 ligation: evidence for augmented NK cell function complementing ADCC. Cancer Immunol Immunother. 2013;62:1841-1849. 